www.conferenceie.ase.ro

\title{
DIGITIZED GOVERNANCE TO MITIGATE HUMAN-RELATED RISKS: A SOFTWARE BASED ON OVERALL EARLY DETECTION
}

\author{
Magali DUBOSSON \\ University of Applied Sciences and Arts Western Switzerland \\ magali.dubosson@hefr.ch \\ Emmanuel FRAGNIERE \\ University of Applied Sciences and Arts Western Switzerland \\ emmanuel.fragniere@hevs.ch \\ Nathalie JUNOD \\ University of Applied Sciences and Arts Western Switzerland \\ nathalie.junod@hesge.ch \\ Samuele MEIER \\ University of Applied Sciences and Arts Western Switzerland \\ samuele.meier@hefr.ch \\ Sacha VARONE \\ University of Applied Sciences and Arts Western Switzerland \\ Sacha.varone@hesge.ch
}

\begin{abstract}
Human workplace risk can be addressed as a business management risk and not only as a medical problem. According to Enterprise Risk Management (ERM), risk is what prevents the achievement of a business objective. The most famous ERM standards are COSO ERM and ISO 31000 and include all kinds of risk categories. However, no category specifically focuses on human risk as a business risk. Even though these risks are recognized by experts as significant risks, their identification at the global level of the company and especially their evaluation remain very complex. In this paper, we propose a brief literature review of models and questionnaires that make it possible to identify and probe these human risks at work. Our goal is to use proven scientific knowledge to create a regular, fast and ergonomic bottom-up data collection system to achieve an overall human risk score for companies. This score can then be integrated into an enterprise risk mapping and allow for better governance that also integrates human risks alongside more traditional risk categories such as operational, financial, strategic and compliance risks. The challenges of our research lie mainly in the relevant and simplified collection of company data and in the definition of an overall human risk score that will be based in a further research on advanced statistical methods.
\end{abstract}

Keywords: computer software, criteria for decision-making under risk and uncertainty, financial risk and risk management

JEL classification: L86, D81, G33

DOI: $10.12948 / \mathrm{ie} 2019.04 .13$

\section{Introduction}

At the European level, initiatives call for a more restrictive legal framework in order to ensure a high quality environment for workers. Various researches (e.g. at the European Union level [1]) highlighted the damaging effects of toxic environments on human health and on the performance of organizations. Companies cannot efficiently fight a toxic environment and its detrimental impact if they do not have the tools to monitor and manage human-related risks. 
Enterprise Risk Management (ERM) approaches are very popular today and often implemented through the COSO and ISO frameworks, although the weak link remains the human part. The most prominent examples are currently non-conformity risks, data leaks and cyber risks. However human-related comprise far more risks such as fraud, lack of performance or burnout. As we aim to develop a tool enabling to identify and mitigate human-related risks, the research question to be answered is: "How to build an organization's checkup tool for human risks?" This question to be answered requires a transdisciplinary approach. That question can be subdivided into four main sub-questions: 1 . "What are the necessary data to collect to ensure that human-related risks will be identified and mitigated?", 2. "How to collect data from and about the employees?", 3. "How to integrate these data into one meaningful score?", 4. "When does the system have to release an alert?". As we are in the beginning of this research, in this paper, we address the first sub-question, that is "What are the necessary data to collect to ensure that human-related risks will be identified and mitigated?"

In general, the notion of risk includes two elements: probability on the one hand and impact on the other. The concept of risk therefore refers to the link between the probability of exposure to a hazard and the consequences (monetary, physical, psychological, etc.) likely to occur. Moreover, when we talk about risk, we focus more on the origin and not on the manifestation and consequences. The French Ministry of Labor, Employment and Health has commissioned an in-depth study on the topic of psychosocial risks at work and defines them as "risks to mental, psychological and social health caused by the conditions of employment and the organizational and relational factors that may interact with the mental functioning of individuals" [1].

In the context of work, the notion of risk must be understood as the probability of the occurrence of disorders originating in the professional environment. Several well-known models and related questionnaires arising from the scientific literature permits to assess precisely this notion of human risks at work. However, these questionnaires are long and rather usable for in-depth studies. In this research, we have created a software module that is to be integrated in a conventional ERM (Enterprise Risk Management) system, and that does not require a lot of data and provides an "overall enterprise temperature" of human risk for early detection. The goal is that the enterprise can if necessary response in a timely manner before it is too late.

In this short paper, in Section 2, we present three well-known scientific models related to the notion of work experience. In Section 3, we show, how based on models presented in Section 2, how we have created a questionnaire of reduced size for implementation in an ERM (Enterprise Risk Management) software. In Section 4, we present the new risk visualization framework that we have developed to adapt to traditional ERM reporting. In Section 5, we conclude and indicate further research directions.

\section{Scientific models interested in the work experience}

In this short paper, we briefly present three well-known models (demand-autonomy [3], effortreward imbalance [4] and Maslach burnout inventory [5]) related to work experience. All these models are at the origin of questionnaires often used to conduct field studies related work experience (see Section 3).

In Karasek's model [3], also known as the demand-autonomy model, a work context characterized by a combination of low decision-making autonomy and high psychological demand is assumed to increase the risk of developing a physical or mental health problem. More precisely, the psychological demand is the amount of work to be done, the time constraints related to this work and the mental demands. Decision-making autonomy refers to the worker's ability to have control over the tasks the employee must perform but also over the 
possibility of developing his/her skills. Future research has added social support as a third component of the model. In general, it reflects the interactions experienced at work, with colleagues and the hierarchy. Social support therefore intervenes, when it is present, as a modulator of tension at work. In other words, in case of difficulty, social support can help the person by making them feel supported, or on the contrary aggravate the situation with a feeling of abandonment by their colleagues/leaders.

Siegrist's model [4], also known as the effort-reward imbalance model, is based on the hypothesis that a combination of high effort and low rewards will allow pathological reactions to occur, both physiologically and emotionally. The high effort variable can come from two sources: external and internal. External origin includes high demands at work such as having a lot of responsibility or being often interrupted. Otherwise, it may be an intrinsic effort that translates attitudes into motivations for excessive engagement in work. With regard to the latter aspect, a sense of duty, a need to surpass oneself or the self-gratifying experience of facing challenges or controlling a situation can be explained. If low rewards such as unsatisfactory pay, lack of esteem and respect at work and low job security are present in conjunction with high effort, then the person may be faced with a risky situation.

Burnout in the BMI (Maslach Burnout Inventory) model [5] is defined as a psychological syndrome of exhaustion, cynicism and ineffectiveness, experienced in response to chronic stressors. Engagement (versus burnout) as proposed by this model [5] is a different construct from others typically proposed by organizational psychology such as organizational commitment, job satisfaction or job invasion. Organizational commitment refers to the employee's allegiance to the organization that gives him/her work. The focus is on the organization, while the commitment focuses on the work itself. Job satisfaction is the extension of the idea of work as a source of the need for achievement and satisfaction, but does not include the person's relationship with the work itself. Organizational involvement is similar to the concept of involvement contained in engagement with work, but does not include the dimensions of energy and efficiency. Therefore, engagement provides a more complex and indepth perspective of an individual's relationship.

\section{From questionnaires based on scientific literature to a reduced risk questionnaire}

The objective of our project is to identify the most significant elements and combine them into a single score at team and department level. Indeed, for companies, what really matters are the stress or dissatisfaction factors that lead to harmful behavior that prevent managers and their teams from achieving their objectives. The developed module will be incorporated into the oxial risk solution and will collect and analyze the relevant data to calculate a single score measuring the level of human risk. Consequently, based on questionnaires from the scientific literature, originally elaborated from work experience models (see section 2), published in [6], [7], [8], [9] and [10], we have retained 171 relevant questions. As most of these questions overlap partially or totally, we have arrived by our analysis grounded on the scientific literature at the following 15 typical topics:

1. Planning / organization

2. Decisions / initiatives

3. Variety of tasks

4. Meaning / importance of the work

5. Creativity / complexity

6. Socialization / support

7. Hierarchy support

8. External relations / customers

9. Recognition / reward 
www.conferenceie.ase.ro

10. Material resources

11. Workload

12. Justice

13. Sense of security

14. Feeling satisfied / uncomfortable

15. Self-confidence / competence

Based on these 15 topics, statements are currently developed (test phase) and are answered based on the following 5-point likert scale: "Strongly Agree, Agree, Neutral, Disagree, Strongly Disagree". For instance, a statement we are considering for topic 1 (Planning / organization) is "I am dissatisfied with the organization that has been imposed on the work I do".

This will allows us to create a very short questionnaire in our data collection system that covers most of the most recognized questionnaires in the scientific literature and can also be easily loaded from an app or tablet. This latter phase will be addressed in a research paper addressing our second sub-question: "How to collect data from and about the employees?". Once the expected data is collected in a weekly manner in the risk register, a unique score will be calculated for each business unit of a given company. The development of this unique score based on statistical approaches will be addressed in a research paper addressing our third subquestion: "How to integrate these data into one meaningful score?".

\section{Designing a visualization interface for human risk identification}

The risk management process [11] can be summarized as shown in Figure 1. In step one, business objectives must be defined. Then risks that can prevent the achievement of the business objectives must be inventoried (i.e. step 2). These risks are then evaluated by calculating their probability and impact (i.e. step 3). They are visualized trough a risk map. In step 4, treatments are in place to give an appropriate response to the significant risks by either mitigating, avoiding or transferring them. Finally, step 5 or risks controls allow to monitor whether the treatment measures are effective. It is an iterative process. In general, in a large company, one or two full cycles are carried out per year.

The human risk module has been designed to be directly integrated into an ERM software. However, the logic of the human risk calculation will be different from the traditional approach where the probability is multiplied by the impact. Indeed, the human risk will correspond to a single score that gives a severity or criticality according to a predetermined color (green=small risk, yellow=medium risk, ref=high risk). Consequently, the human risk matrix will be, as shown in Figure 2, structured the following way: on the left hand side, each row shows a given BU (Business Unit) and then, on the right hand side, we will be able to see the evolution over time (here week after week) of the aggregated human risk measure. Both tools (risk map and human risk matrix) will therefore be combined, which will provide managers with an even greater depth in terms of enterprise risk management diagnosis.

The main motivation for this, is that the human risk is already contained in each given risk inventoried in the enterprise risk map and thus should not be presented as an individual risk. Thanks to this new kink of risk reporting combining both the classical risk map and the dynamic human risk matrix, triggers calling for risk treatments and monitoring through controls will be addressed in a research paper addressing our fourth sub-question: "When does the system have to release an alert?". 
www.conferenceie.ase.ro

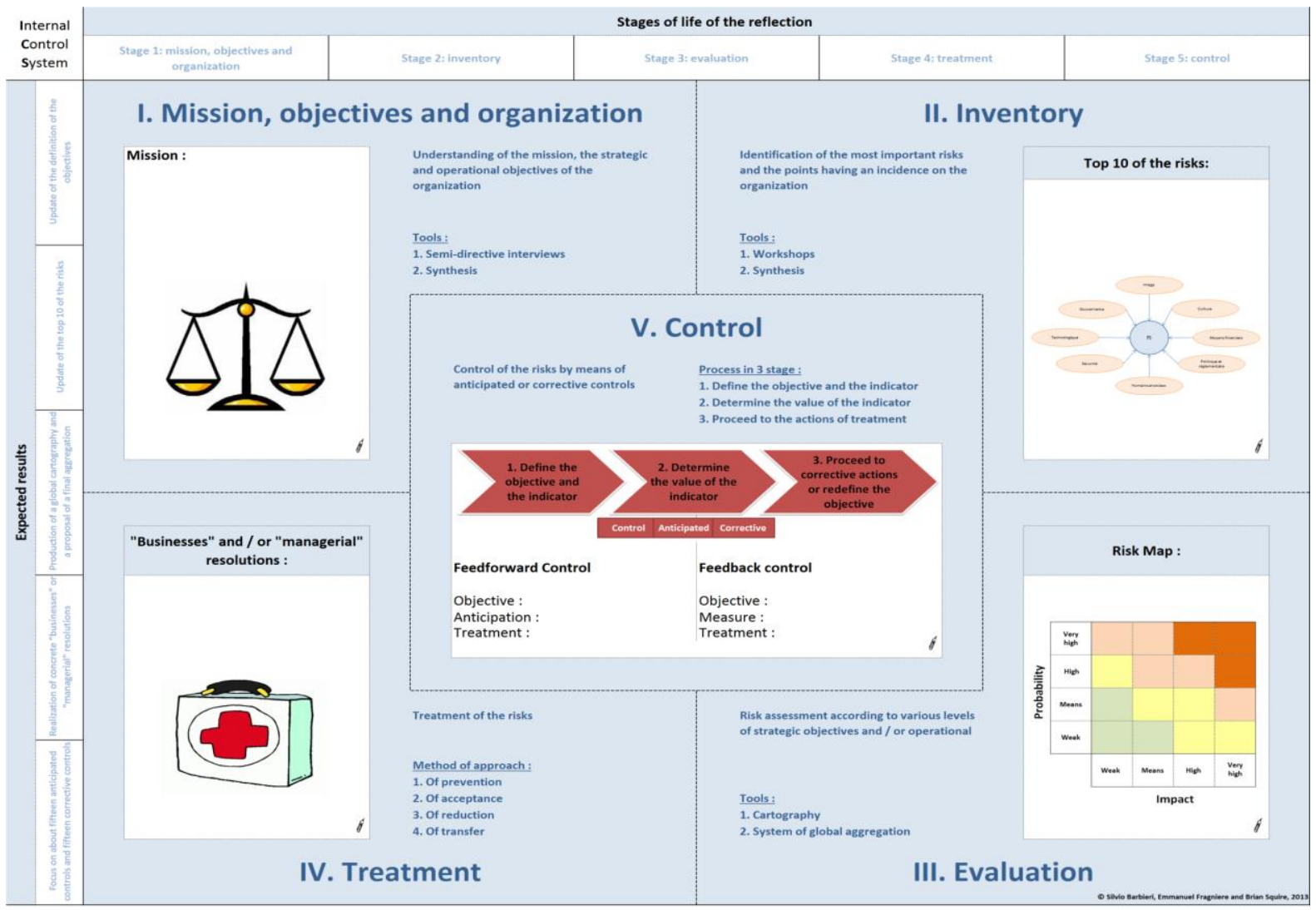

Figure 1. The generic Enterprise Risk Management (ERM) process, valid for both COSO and ISO standards

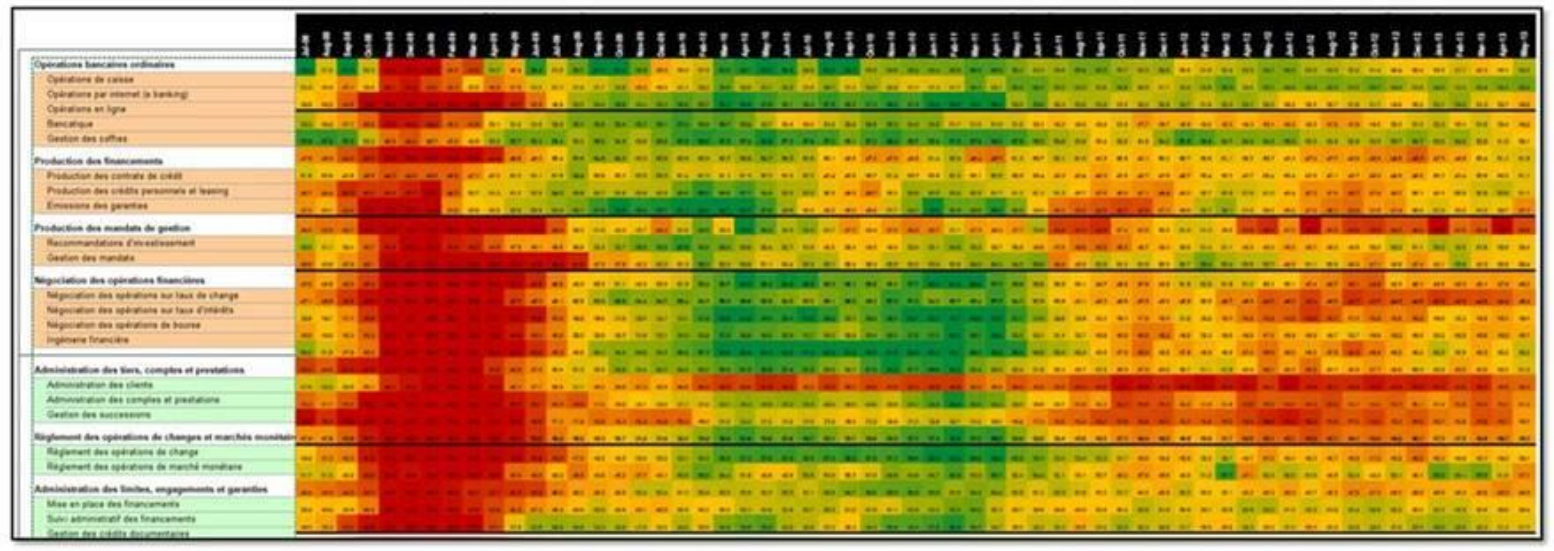

Figure 2. Aggregate dynamic human risk matrix according to business unit (list in the left column)

\section{Conclusion}

Managers need new means to manage human-related risks to assess human risk. Companies need an indicator which measures human risks, monitors its trends and benchmarks among departments and products of companies. We aim at developing a human risk platform accessed through an SaaS (Software as a Service). Our solution relies on data collection and processing in order to measure human-related risks, analyses data and provide a unique score for the company. Research challenges mainly lie in a regular and rapid data collection process among employees and in the definition of the score through statistical methods. In this paper, we have presented the concept of our human risk management solution. The first step of this research (the data collection phase) is currently implemented in a large Swiss company as a module of the oxial Risk solution for testing purposes. In the future, we hope that our solution will enable 
www.conferenceie.ase.ro

to address in a pragmatic and relevant manner human-related risks that are at present not properly covered by most ERM (Enterprise Risk Management) software. Human-related indicators will be combined with more traditional indicators to generate alerts that are working as early signals. Consequently, our ERM software solution will favor feedforward controls [12] (as opposed to feedback controls) in order to prevent risks to arise rather than to deal with damages when observed. Feedforward controls correspond thus to important further research directions in ERM that we will pursue to provide practical anticipated and preventive responses to human risks.

\section{Acknowledgment}

We gratefully thank the innovative promotion agency (Innosuisse, Switzerland, Project No. 28878.1) for financial support of the project and technical guidance, as well as our Innosuisse project partner oxial and in particular, Eric Berdeaux and Charles Wainwright.

\section{References}

[1] Y. Clot and M. Gollac, Le Travail peut-il devenir supportable ?, Paris: Armand Colin, 2014.

[2] S. Leka, A. Jain, T. Cox and E. Kortum, "The development of the European framework for psychosocial risk management: PRIMA-EF," Journal of Occupational Health, vol. 53, no. 2, pp. 137-143, 2011.

[3] R. Karasek and T. Theorel, Healthy Work: Stress, Productivity, and the Reconstruction of Working Life, New York: Basic Books, 1990.

[4] J. Siegrist, K. Siegrist, I. Weber, "Sociological concepts in the etiology of chronic disease: the case of ischemic heart disease," Social Science and Medicine, vol. 22, no. 2, pp. $247-$ 253, 1986.

[5] C. Maslach, S.E. Jackson, "The measurement of experienced burnout," Journal of organizational behavior, vol. 2, no. 2, pp. 99-113, 1981.

[6] F.P. Morgeson, S.E. Humphrey, "The Work Design Questionnaire (WDQ): Developing and validating a comprehensive measure for assessing job design and the nature of work," Journal of Applied Psychology, vol. 91, no. 6, pp. 1321-1339, 2006.

[7] S. Cohen, T. Kamarck, R. Mermelstein, "A global measure of perceived stress," Journal of Health and Social Behavior, vol. 24, no. 4, pp. 385-396, 1983.

[8] M.P. Leiter, C. Maslach, "Six areas of worklife: A model of the organizational context of burnout," Journal of Health and Human Resources Administration, vol. 21, no. 4, pp. 472 489, 1999.

[9] E. Diener, R.A. Emmons, R.J. Larsen and S. Griffin, "The satisfaction with life scale," Journal of Personality Assessment, vol. 49, no. 1, pp. 71-75, 1985.

[10] W.B. Schaufeli, A.B. Bakker and M. Salanova, "The measurement of work engagement with a short questionnaire: A cross-national study," Educational and Psychological Measurement, vol. 66, no. 4, pp. 701-716, 2006.

[11] S. Barbieri, E. Fragniere, M. Sitten and G. Zambrano, "Proposal of a methodology to integrate the human factor in the service blueprint," Journal of Advanced Management

Science, vol. 1, no. 2, pp. 207-213, 2013.

[12] M. Baker and M. Bourne, "A governance framework for the Idea-to-launch process development and application of a governance framework for new product development," Research-Technology Management, vol. 57, no. 1, pp. 42-48, 2014. 